\title{
Supravalvular Pulmonary Artery Stenosis
}

National Cancer Institute

\section{Source}

National Cancer Institute. Supravalvular Pulmonary Artery Stenosis. NCI Thesaurus. Code C99066.

Stenosis of the pulmonary artery that occurs above the valve. 